\title{
LA ÉTICA PROFESIONAL PEDAGÓGICA Y SU INCIDENCIA EN LA EVALUACIÓN DEL DESEMPEÑO PROFESIONAL DEL DOCENTE
}

\author{
PhD. Alejandro Lema Cachinell \\ Instituto Tecnológico de \\ Formación \\ alejandrol@formacion.edu.ec
}

\author{
MSc. Yaneiris Castro Durand \\ Instituto Tecnológico de \\ Formación \\ martalema@formacion.edu.ec
}

\author{
Lic. Daniel Zaldívar Almarales \\ Instituto Tecnológico de \\ Formación \\ daniel.zaldivar@formacion.edu.ec
}

Palabras claves: ética, evaluación, desempeño profesional.

Keywords: ethic, evaluation, professional performance.
Recibido: 06 de enero de 2017

Aceptado: 27 de enero de 2017

\section{RESUMEN}

La presente investigación hace levantar la mirada para realizar un examen crítico del quehacer profesional en términos de captar elementos del actuar del docente, donde se reflejan los modos de comprender y regular el comportamiento profesional favorablemente; pero, sin ser muy categóricos, se puede plantear que el abordaje científico del aspecto ético dentro de la evaluación del desempeño profesional del docente todavía no alcanza la jerarquía que este particular merece. Se analiza el comportamiento de la ética profesional pedagógica y su incidencia en la evaluación del desempeño profesional del docente.

\section{ABSTRACT}

The present research presents a critical examination of the professional performance in terms of capturing elements of the teacher's action, where the ways of understanding and regulating professional behavior are reflected. However, without being very categorical, it can be argued that the scientific approach of the ethical aspect within the evaluation of the professional performance of the teacher still does not reach the hierarchy that this particular deserves. An analysis of the behavior of professional pedagogical ethics and its impact on the evaluation of the professional performance of teachers is proposed. 


\section{INTRODUCCIÓN}

La evaluación como componente del proceso docente educativo, debe concebirse como proceso y resultado que conduzca a la valoración objetiva del desempeño de los evaluados y que estimule las transformaciones cualitativamente superiores en estos. Se comparte el enfoque de la evaluación como exigencia intrínseca del acto educativo, es decir, que se identifica la categoría evaluación como componente esencial del proceso y consustancial a este, considerando su lugar y papel correspondiente, sin absolutizaciones. Se destaca el carácter integrador, holístico y personológico de la evaluación, como un hecho personal, en el que se involucran de manera activa y protagónica los docentes, estudiantes y colectivos donde está insertado el evaluado.

Por lo tanto, la evaluación del desempeño profesional del docente requiere de una indiscutible plataforma ética de todos los sujetos que, de una forma u otra, intervienen en ella. Sin embargo, son escasas las referencias teórico-prácticas respecto al carácter ético-humanista de la evaluación docente y a su relación con el desempeño profesional.

\section{DESARROLLO}

La evaluación se valora como proceso y resultado importante para lograr la formación armónica del alumno y el grado de excelencia de una institución académica a partir de sus objetivos. Desde este punto de vista, la evaluación influye en el personal docente, y los directivos para las modificaciones e innovaciones en la planificación, organización y ejecución de los procesos pedagógicos y en la reorientación de su accionar docente.

En tal sentido la evaluación necesita de una visión ética que le permita tener una característica diferente contribuyendo de esta manera al desarrollo cualitativo y cuantitativo del docente.

La ética se constituye en una de las ramas de la filosofía. En los años 50 del siglo $X X$, esta se transforma en una rama de la filosofía o en una ciencia filosófica que estudia la moral en su integridad y el comportamiento humano en las diferentes esferas de la actuación.

La dialéctica materialista aporta una nueva concepción integradora del mundo y brinda los fundamentos teóricos y los principios metodológicos para el desarrollo del conocimiento ético con toda su connotación, tanto en la comprensión de la ética en su desarrollo histórico como sobre la moral, la cual es concebida como un fenómeno de naturaleza histórico social, y su complejidad se expresa en las leyes de la dinámica de su estructura y funciones, en interacción con toda la actividad y comunicación de los seres humanos, cuyas cualidades distingue la cultura de cada época.

Al respecto se asume que la aparición de la moral responde a la necesidad objetiva de regular las relaciones de los seres humanos que conviven en sociedad (individuo - sociedad), sobre la base de la correlación de los intereses individuales y sociales y del control de la voluntad en la conciencia, profundamente marcados por lo clasista, en lo cual los valores, como parte de la conciencia moral, presentes en los 
ideales sociales, principios, normas, escalas y juicios de valor, desempeñan un papel primordial.

Muchos autores definen la ética de diversas maneras; pero, como aseguran Santos (1989), Cano (1999) así como Celeiro (2012), su final es encontrar el bien, estudiando los fundamentos, causas y razones de lo bueno y lo malo de la conducta humana; esto implica una reflexión de los actos morales y una revisión crítica de la validez de dicha conducta.

En contraste, se opina que la ética es el uso de la herramienta de la razón para generar reglas que guíen el juicio en circunstancias tanto generales como particulares. Con ello, se obtendrá una mayor visión y una amplia gama de alternativas que se deben de escoger para poder encontrar el mejor camino para el bien personal y común.

En las definiciones analizadas se destaca la ética en tres áreas:

- La ética social que consta de reglas las cuales ayudan a que las personas puedan variar de un grupo social a otro.

- La ética trascendental donde se explica el concepto del bien y el mal y de la justicia e injusticia, esto se aplica equitativamente si se toma en cuenta el grupo social, la demografía, y la cultura.

- La ética táctica que se basa en obedecer reglas y leyes para evitar infracciones o castigos.

Resulta necesario, a los efectos de esta investigación, enfatizar en que la ética profesional pedagógica visualiza los rasgos esenciales los cuales deben acompañar la evaluación del desempeño profesional no sólo de los evaluados; sino también de los propios evaluadores, quienes deben responder a criterios e indicadores que regulen con justeza e integralidad el desarrollo cognitivo y afectivo, con el propósito de alcanzar los objetivos personales, institucionales y de la sociedad.

En la actualidad se requiere cada vez más de guías que orienten tanto en los aspectos más técnicos de la evaluación como en los principios éticos que esta debe contemplar. Al decir de este investigador, la evaluación es una cuestión ética más que una cuestión técnica, porque interactúan personas que elaboran juicios de valor sobre una situación determinada en la cual están involucradas otras personas. Esta idea la corrobora Santos (1989), al referirse a los efectos negativos que pueden producirse cuando la falta de ética está presente en el proceso evaluativo. Por ejemplo, cuando:

1. Se descalifica el proceso de la evaluación por considerarlo poco científico o poco significativo.

2. Se atribuyen los resultados de la evaluación a diversas causas externas.

3. Se manipulan las conclusiones sin tener en cuenta indicadores, objetivos e integralidad del desempeño.

Hay coincidencia en los autores sobre el componente ético, y casi todos subrayan que no debe ser una actividad punitiva, ni servir para establecer normas, ni para prescribir, sino, para interpretar, cambiar y mejorar el desempeño docente para bien del propio docente, la institución y la sociedad en su conjunto. 
Las cualidades éticas profesionales del docente como el humanismo, la modestia, la sencillez, la honestidad, la perseverancia, la dedicación al trabajo, el espíritu de sacrificio, el sentido de lo justo, su celo profesional, así como sus elevados ideales morales son las que lo motivan a ser mejor ser humano, mejor profesional y repercuten inquebrantablemente en el desarrollo de sus capacidades, competencias profesionales y en el excelente desempeño profesional.

Desde la perspectiva sociológica, la evaluación del desempeño profesional constituye una categoría de gran significación para la vida de una sociedad, pues da cuenta de la reflexión acerca del accionar educativo de los docentes y su consecuente repercusión social. Blanco (2004) considera que en la formación de las nuevas generaciones en una sociedad tienen gran responsabilidad los educadores.

La relación del sujeto con la cultura y la sociedad a través de la educación recibe el nombre de proceso de socialización: Vigotsky (1998- 2000); Chávez (2003); Blanco (2004). Quiere decir que el hombre cuando se educa a través de las diferentes agencias educativas se socializa y se da una relación dialéctica entre la individualización y socialización de este.

En el proceso de evaluación de un docente deben participar diferentes agencias o agentes sociales que se relacionan con su desempeño, los cuales influyen de una manera $u$ otra en su actuación profesional y en su evaluación, díganse los estudiantes, la familia, los compañeros de trabajo, los procesos de comunicación social, la institución. A su vez el buen desempeño profesional del docente es vital para el desarrollo social.

En este sentido, en la concepción de la evaluación en Ecuador han existido algunas incoherencias respecto a la evaluación del desempeño profesional del docente de los institutos superiores tecnológicos, donde ha fallado en gran medida el proceso de socialización, primando la subjetividad del evaluador, su base teórica- conceptual se ha sustentado, en gran medida, en función de objetivos medibles y observables de tipo conductual, que responden a un paradigma evaluativo centrado en productos.

Lo anteriormente expuesto repercute de forma negativa en la integralidad de la evaluación de los docentes, ya que prima el tecnicismo en el manejo de las taxonomías de los objetivos, indicadores y contenidos de la evaluación, donde a veces se desvaloriza la repercusión individual-social que genera este enfoque reduccionista.

La Ley de Educación Superior, expedida en el año 2010, es crucial en este proceso; a partir de su publicación se establece la obligatoriedad de evaluar las instituciones de educación superior, aunque no fue suficientemente explícita para que tuviera el impacto social deseado y se convirtiera en un documento de referencia para que la evaluación del desempeño fuera más ética y humanista.

En correspondencia con lo expuesto, Ecuador estructura el Plan Nacional del Buen Vivir 2013-2017, donde se manifiesta que se debe potenciar el rol de docentes y otros profesionales como actores claves en la construcción del buen vivir en una sociedad cada vez más próspera y sustentable, mejorar la oferta de la formación de docentes y otros profesionales de la educación, en el marco de una educación integral, inclusiva e intercultural. 
En lo socio - económico - cultural se valora de manera pertinente, desde el Plan Nacional del Buen Vivir (2013-2017), que el país deje de ser predominantemente extractivista para pasar a ser un país de generación y productividad, por lo que necesita realizar un cambio en la matriz productiva de Ecuador, donde desempeña un rol importante la educación a favor del desarrollo de la sociedad.

En tal sentido, la educación en los institutos tecnológicos desempeña un rol esencial para el desarrollo social, donde la calidad y pertinencia de los resultados profesionales de sus maestros y profesores son imprescindibles, lo cual demanda un conjunto de acciones intencionadas benefactoras a la sociedad, entre ellas la de formar estudiantes calificados y competentes, de manera que puedan enfrentar los retos laborales y profesionales en el dominio de la ciencia, la técnica y la tecnología que requiere la sociedad ecuatoriana.

Desde la psicología, la evaluación del desempeño profesional contribuye a desarrollar la personalidad integral de los docentes a pesar de su diversidad, así como la de sus estudiantes. Se toma en consideración las características individuales de los docentes, estudiantes, incluso de los directivos en sus diferentes niveles de desarrollo, insuficiencias y potencialidades, para promover en ellos el desarrollo hasta el límite de sus posibilidades; pues no se podría pretender que todos lleguen a un mismo nivel de desarrollo, ni que sean perfectos, pero sí perfectibles como condición humana.

Según Castellanos (2003) y González (1983) el vínculo de lo cognitivo y afectivo de la personalidad se expresa en el proceso evaluativo, a través del cual se llega a alcanzar niveles superiores de autorregulación, autodeterminación, autodesarrollo y autoperfeccionamiento, siendo importante aplicarlo durante el proceso evaluativo para generar un clima afectivo motivacional favorable con el contenido cognitivo instrumental de la evaluación.

Se asume el paradigma psicológico de Vigotsky (2000) el que permite sustentar la evaluación como un proceso de apropiación histórico social mediante la actividad del sujeto y en la comunicación con otras personas implicadas en él mismo, para alcanzar el desarrollo integral.

Los presupuestos vigostskianos permitieron advertir por qué y cómo se inserta el docente en los diferentes espacios socioculturales en que desarrolla su labor y fuera de ella y su papel como mediador fundamental en esos escenarios, en su interrelaciones e interacciones con el estudiantado, el grupo, el colectivo de docentes, la familia, la comunidad, y en la sociedad en general.

De manera más particular se asumen importantes referentes pedagógicos y didácticos que le dan sustento a la evaluación como categoría esencial en los procesos educativos de cualquier institución pedagógica, tales como: Castro (1999); Álvarez (2001); Remedios (2003); Addine (2004); Miranda (2007); Ferrer (2006); Casassus (2008); Perassi (2008); Horruitiner (2009).

El autor coincide con Scrive (2009), al valorar la evaluación como un proceso sistemático de recogida de datos incorporados al sistema general de actuación educativa, que permite obtener información válida y fiable para formar juicios de valor cerca de las diferentes situaciones que pueden darse, con vistas a la toma de decisiones para mejorar la actividad educativa valorada. 
Es importante resaltar lo expresado por Mena (2004, p. 165) en el libro Didáctica: Teoría y práctica, que la evaluación se convierte en un proceso complejo, personalizado, de reflexión, regulación y ayuda, así como un conjunto de actividades motivadoras que permite una valoración consciente de la realidad, ante la cual se proponen alternativas de cambio.

De manera que se considera a la evaluación como un proceso sistemático de valoración del resultado del trabajo de directivos, maestros, alumnos y padres, encaminado a verificar si el conjunto de acciones pedagógicas o educativas se ha llevado a cabo con eficiencia, permite comprobar y controlar el proceso educativo integralmente.

Así, la evaluación constituye un eslabón esencial del proceso docente educativo, la que se interrelaciona dialécticamente con otros componentes, cuyas funciones instructiva, educativa, de diagnóstico, de desarrollo y de control le dan una connotación particular a este proceso como un todo.

En tal sentido se contextualiza lo expresado por Horruitiner (2009, p.175) acerca de que la evaluación se asume como un eslabón, una parte, del proceso de formación el cual ha venido transitando desde un enfoque acumulativo-cuantitativo, propio de etapas anteriores de desarrollo a uno ético integrador, centrado en los procesos sustantivos del docente (investigación, vinculación, docencia y gestión administrativa) evitando de esta manera la subjetividad que se puede generar en la evaluación del desempeño profesional del docente.

\section{CONCLUSIONES}

La evaluación, en su concepción más general, permite retroalimentar acerca del trabajo realizado y adoptar estrategias de intervención pedagógica individualizadas, en una institución, provincia y país. A partir de sus resultados se genera conciencia social, no sólo acerca de la calidad del aprendizaje de los estudiantes, sino también acerca del desempeño profesional de los docentes y directivos y por consiguiente se generan políticas educativas nacionales. En tal sentido en este proceso se precisa de un basamento ético que guíe la evaluación y de esta forma contribuya el desarrollo del docente en su labor profesional. 


\section{REFERENCIAS BIBLIOGRÁFICAS}

Addine, F.; Mena, E. (2004). Didáctica: Teoría y práctica. La Habana, Cuba: Editorial Pueblo y Educación.

Álvarez, R. (2000). La evaluación del sistema educativo cubano, una experiencia. Madrid, España: Revista Educación, No.321.

Blanco, P. (2004). Hipótesis, variables y dimensiones en la investigación educativa. En Compendio de Pedagogía. La Habana, Cuba: Editorial Pueblo y Educación.

Cano, E. (1999). Evaluación de la calidad educativa. 2da edición. Madrid, España: Editorial Muralla, F.

Casassus, J. (2008). Una nota acerca de la evaluación en educación. Venezuela: Revista CENDES.

Castellanos, B. (2003). Aproximación a un marco conceptual para la investigación educativa. La Habana, Cuba: Editorial Pueblo y Educación.

Castellanos et al. (2003). La formación de la competencia investigativa. Una necesidad y una oportunidad para mejorar la calidad de la educación. La Habana, Cuba: Evento Internacional de Pedagogía.

Chávez, J. (1997). Retos actuales de las Teorías Educativas. Cuba: Conferencia para Pedagogía' 97.

. (2003). Tendencias contemporáneas para transformar la educación en los países iberoamericanos. México: Editorial INAES.

Celeiro, A. (2012). La cultura ético-axiológica humanista del profesional de la educación. UCP. Frank País García. Santiago de Cuba: Recuperado de http://www.monografias.com/trabajos96/cultura-etico-axiologicahumanista-del-profesional-educacion/cultura-etico-axiologica-humanistadel-profesional-educacion6.

Ferrer, A. (2006). Cooperación internacional en evaluación de la educación en América Latina y el Caribe: Análisis de la situación y propuestas de actuación. Cúpula das americas-linha 2. Estudios internacionales- LLECEIEA- OCDE- OEI Proyecto INES- WEI- PISA- TIMSS-RLS- PIRLS

González, M. (1998). La evaluación en las instituciones democráticas: discusión sobre la ciencia y la ética de sus procedimientos. Universidad San Carlos de Guatemala: Recuperado de http//www.campusoej.org/salactsi/mgonzalezhtm.

González, M. y Reinoso, C. (2002). Nociones de Sociología, Psicología y Pedagogía. La Habana, Cuba: Editorial Pueblo y Educación.

Horruitiner Silva, P. (2009). La universidad cubana modelo de formación. La Habana: Editorial Universitaria. 
Mena. (2004). Didáctica teoría y práctica. En (p. 165). La Habana. Cuba: Pueblo y Educación.

Miranda, A. (2007). Opinión de los alumnos sobre el desempeño de sus profesores. Una herramienta para obtener indicadores sobre la práctica docente. México, FES-Iztacala: Tesis de licenciatura.

Perassi, Z. (2008). La evaluación en educación: Un campo de controversias. Argentina: Ediciones del Proyecto y Ediciones LAE, San Luis - Argentina.

Remedios, J. (2001). Vías que contribuyen a transformar los modos de actuación en el desempeño profesional del docente. Informe final al Proyecto asociado al Programa Ramal II CDIP, ISP Capitán Silverio, Blanco Núñez, Sancti Spíritus.

Santos, M. (1989). Evaluación educativa: un proceso de diálogo, comprensión y mejora. Colección Respuestas educativas. Buenos Aires, Argentina: Editorial Magisterio del Río de La Plata.

Scriven, M. (2009). Método evaluativo orientado hacia el cliente. Recuperado de: http://www.slideshare.net/richardecg/exposicion-michael-scriven

Vygostky, L. (1980). Desarrollo de los procesos psicológicos superiores. La Habana, Cuba: Editorial Pueblo y Educación. 